\title{
Cytotoxicity of Vibrio vulnificus cytolysin on pulmonary endothelial cells
}

\author{
Jong-Suk Kim ${ }^{1}$ \\ 1 Department of Biochemistry, School of Medicine and \\ Institute for Medical Science, \\ Chonbuk National University, Chonju 561-756, Korea
}

Accepted 26 May 1997

Abbreviations: HU, hemolytic unit; LDH, lactate dehydrogenase cells in culture, and acted as a vascular permeability factor. Even sub-microgram amount of the cytolysin is fatal to mice when injected intravenously (Gray and Kreger, 1985; Park et al., 1996). The extensive tissue damage which occurred in mice after subcutaneous injection of the cytolysin, and was very simillar to that observed during $V$. vulnificus wound infections (Gray and Kreger, 1989). These reports suggest that the cytolysin is the major factor in the pathogenesis of $V$. vulnificus infections. Although several lines of investigations on the the action of the cytolysin against mammalian cells such as mast cells (Yamanaka et al., 1990) and erythrocytes (Kim et al., 1993; Park. et al., 1994; Chae et al., 1996) has been carried out, the role of the cytolysin in the pathogenesis of the disease is not well known.

Recently, it has been known that V.vulnificus cytolysin have lethal activity primarily by increasing vascular permeability and neutrophil sequestration in the lung of mice (Park et al., 1996), and causes hypotension in rats (Kook et al., 1996). Rinaldo and Rogers (1986) indicated that septicemia and associated alterations of pulmonary endothelial function such as increased permeability of the pulmonary microvasculature by bacterial toxins are important in the pathogenesis of the acute respiratory distress syndrome.

This paper shows that $V$.vulnificus cytolysin has a direct cytotoxic effect on CPAE cells, a pulmonary endothelial cell line, which may be the target cells of cytolysin in vivo.

\section{Materials and Methods}

\section{Bacterial strain and culture}

A virulent strain of $V$. vulnificus E4125 was kindly supplied by Dr. M. H. Kothary (Department of Microbiology, Virulence Assessment Branch, Center for Food Safety and Applied Nutrition, Food and Drug Administration, Washington D.C.). The strain was cultured in the heart infusion diffusate broth (Gibco, Gaithersburg, U.S.A.) at $37^{\circ} \mathrm{C}$ for $4 \mathrm{~h}$ as described by Kreger et al. (1988).

\section{CPAE cell culture}

The pulmonary endothelial cell line, CPAE (ATCC CCL 209) was obtained from Korea Cell Bank (College of Medicine, Seoul National University, Korea). CPAE cells were cultured in Dulbecco's modified Eagle's medium (DMEM) supplemented with $10 \%$ fetal bovine serum (Gibco), penicillin (100 units $/ \mathrm{ml})$, streptomycin $(0.1 \mathrm{mg} / \mathrm{ml})$ and amphotericin $\mathrm{B}(0.25 \mu \mathrm{g} / \mathrm{ml})$ in a humidified atmosphere of $5 \% \mathrm{CO}_{2}$. CPAE cells were used after trypsinization. 


\section{Preparation of V. vulnificus cytolysin}

The cytolysin was purified to homogeneity from the culture supernatant by ammonium sulfate fractionation, calcium phosphate gel adsorption, quartenary methylamine anionexchange chromatography and octyl-Sepharose CL-4B chromatography as described by Kim et al. (1992).

\section{Assay of cell viability}

Cell viability was determined by Trypan blue dye exclusion method (Rosengard and Cochrane, 1983).

\section{Assay of hemolytic activity}

The hemolytic activity of cytolysin against mouse erythrocytes was determined by the method of Bernheimer and Schwarz (1963). The cytolysin was diluted with phosphatebuffered saline (PBS) $\left(67 \mathrm{mM} \mathrm{Na} \mathrm{HPO}_{4}, 77 \mathrm{mM} \mathrm{NaCl}\right.$, $\mathrm{pH}$ 7.4) containing $1 \mathrm{mg}$ of bovine serum albumin (BSA) per $\mathrm{ml}$. One milliliter of cytolysin was mixed with the same volume of $0.7 \%$ mouse erythrocyte suspensions in PBS-BSA. After incubation at $37^{\circ} \mathrm{C}$ for $30 \mathrm{~min}$ and brief centrifugation, absorbance of hemogolobin in the supernatant was measured. One hemolytic unit $(\mathrm{HU})$ is defined as that amount which liberates half of the hemoglobin under the above conditions.

\section{Release of lactate dehydrogenase (LDH)}

The release of LDH was used as a marker for overt cytolysis. Enzymatic activity of LDH in the culture medium was determined by the method of Whalefeld (1983). Twenty microliters of the supernatant after brief centrifugation was added to $20 \mu \mathrm{l}$ of $172 \mathrm{mM} \beta-\mathrm{NAD}$ and $460 \mu \mathrm{l}$ of Tris/L-lactate (112 mM Tris, $56 \mathrm{mM}$ L-lactate, $170 \mathrm{mM}$ $\mathrm{KCl}, \mathrm{pH}$ 9.3) and incubated. The increase of absorbance for $1 \mathrm{~min}$ at room temperature was monitored at $340 \mathrm{~nm}$. Enzyme release was expressed as the percentage of total enzymatic activity determined by lysing cells with 5 $\mu \mathrm{l}$ of $5 \%$ Triton $\mathrm{X}-100$.

\section{Measurement of ATP}

To measure cellular ATP, CPAE cells were lysed with $5 \%$ trichloroacetic acid. After brief centrifutgation, ATP in the supenatant was determined by the chemiluminescence method using luciferin-luciferase (Ludin, 1978). Twenty microliters of the supernatant was added to $80 \mu \mathrm{l}$ of 100 $\mathrm{mM}$ glycine buffer $(\mathrm{pH} 12.6)$ and $100 \mu \mathrm{l}$ of luciferinluciferase solution, and the chemiluminescences were read by chemiluminometer (Lumat, LB9501). A standard ATP was prepared just before use.

\section{Current recording}

Gigaseals were formed with Sylgard-coated pipette (borosilicate, Kimble) with 4 to 5 megaohms resistance and single-channel currents were recorded by use of the inside-out configuration of the patch clamp method described by Hamill et al. (1981). Channel currents were recorded with an Axo-patch 1D patch clamp amplifier (Axon) and stored on video tapes via digital recorder (PCM-501ES, SONY) for later computer analysis. A pClamp software (Axon) was used for data acquisition and analysis. All experiments were carried out at $22 \pm$ $2^{\circ} \mathrm{C}$ The standard bath and pipette solutions contained $140 \mathrm{mM} \mathrm{KCl}, 2 \mathrm{~m} \mathrm{M} \mathrm{MgCl} 2,5 \mathrm{mM} \mathrm{EGTA}$ and $10 \mathrm{mM}$ HEPES (pH 7.2).

\section{Results and Discussion}

Many studies have reported about the effects of endotoxin on the pulmonary microvasculature (Brigham and Meyrick, 1986). Recently, Park et al. (1996) demonstrated that $V$. vulnificus cytolysin caused lethality primarily by increasing vascular permeability and neutrophil sequestration in the lung of mice. It has been known that Escherichia coli hemolysin increases the permeability of pulmonary artery endothelial cell monolayers (Suttorp, et al., 1990), and the stimulation of polymorphonuclear leukocyte adhesion to endothelial cells by bacterial exotoxins may be relevant in patient with severe local or systemic bacterial infections (Krüll et al., 1996). However, alterations of endothelial cell functions by bacterial exotoxins have received little attention.

In order to determine the binding activity of cytolysin, CPAE cells were incubated with cytolysin at $4^{\circ} \mathrm{C}$. After brief centrifugation, the remaining hemolytic activity of unbound cytolysin in the supernatant was determined (Figure 1). The binding of cytolysin to CPAE cells was so rapid that approximately $50 \%$ of $1 \mathrm{HU}$ of cytolysin was bound to CPAE cells within $1 \mathrm{~min}$. This result was similar to that of erythrocytes (Kim et al., 1993). Viability test for CPAE cells was carried out to discern whether the bound cytolysin induced death of the cells. Cytolysin killed CPAE cells in a dose-dependent manner, approximately $80 \%$ of the cells being dead by treatment with $1.0 \mathrm{HU}$ of cytolysin (Figure 2). These results suggest that the cytolysin can directly induce the death of CPAE cells after binding on the cells.

Bhakdi et al. (1986) proposed that generation of transmembrane pores is the mechanism underlying the action of pore-forming exotoxins on target cells. Kim et al. (1993) demonstrated that the cytotolysis of erythrocyte induced by $V$. vulnificus cytolysin is due to the formation of pores on cell membrane through the three steps; specific binding of cytolysin to the lipid bilayer, formation of small pores by the oligomerization of the cytolysin, and osmotic lysis. In order to determine whether the death of CPAE cells is accompanied by the pore formation, the cells were incubated with the cytolysin and single-channel currents were recorded by use of the inside-out configuration of the patch clamp method (Figure 3 ). The formation of transmembrane pores by cytolysin was evidenced by rapid flow of monovalent ions $\left(\mathrm{K}^{+}\right.$or $\mathrm{Cr}$ ) in the patch clamp 


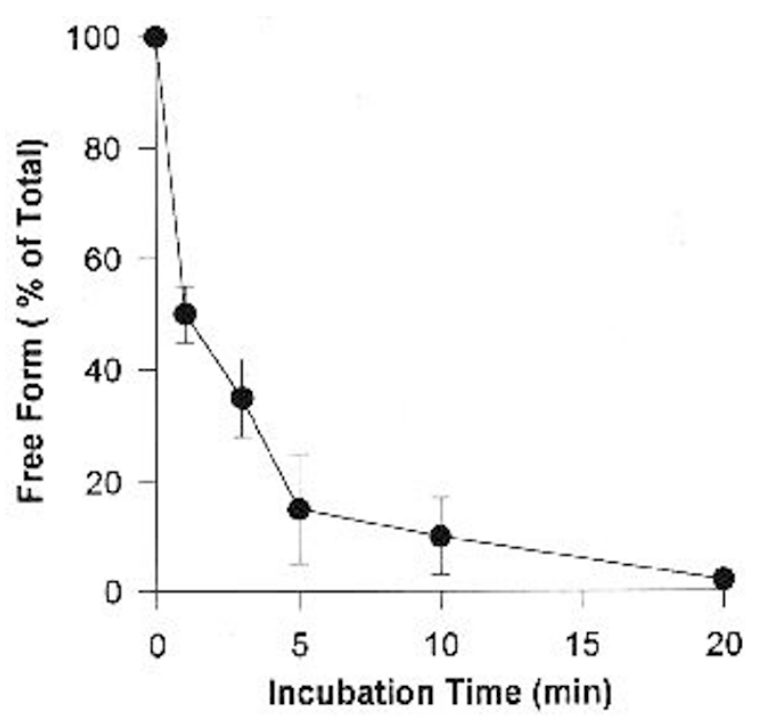

Figure 1. Binding of $V$. vulnificus cytolysin to CPAE cells. CPAE cells $\left(1.3 \times 10^{5}\right.$ cells $/ \mathrm{ml}$ ) were incubated with $1 \mathrm{HU}$ of the cytolysin in a total volume of $1 \mathrm{ml}$ of PBS-BSA at $4^{\circ} \mathrm{C}$. After brief centrifugation, the residual cytolysin in supernatant at the given times was determined by its hemolytic activity as described in "Materials and Methods". The plot dipicts the mean $\pm \mathrm{SD}$ obtained from four separate experiments.

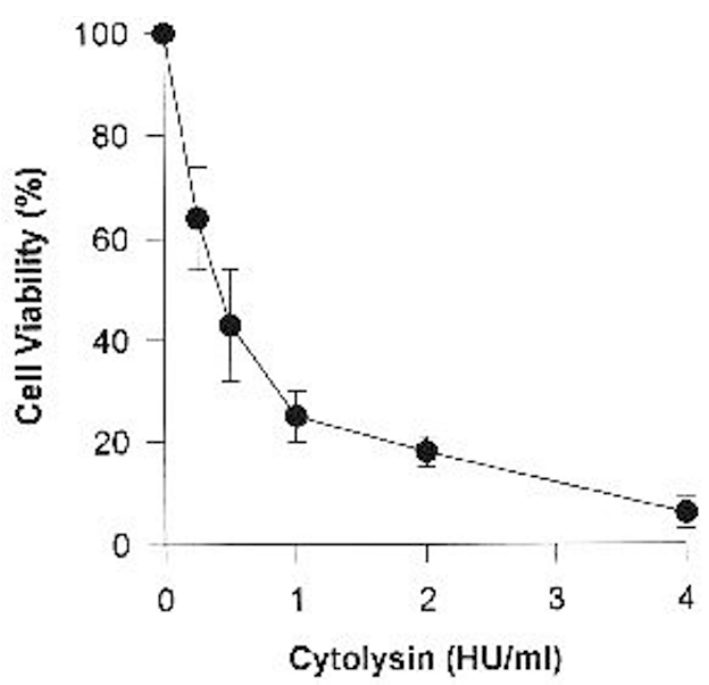

Figure 2. Effect of $V$. vulnificus cytolysin on the viability of CPAE cells. CPAE cells (1 $\times 10^{6} \mathrm{cells} / \mathrm{ml}$ ) were treated with various concentrations of the cytolysin in a total volume of $0.3 \mathrm{ml}$ of PBS-BSA at $37^{\circ} \mathrm{C}$ for $30 \mathrm{~min}$. Cell viability was determined by the ability to exclude trypan blue. Each value denotes the mean $\pm S D$ obtained from four separate experiments

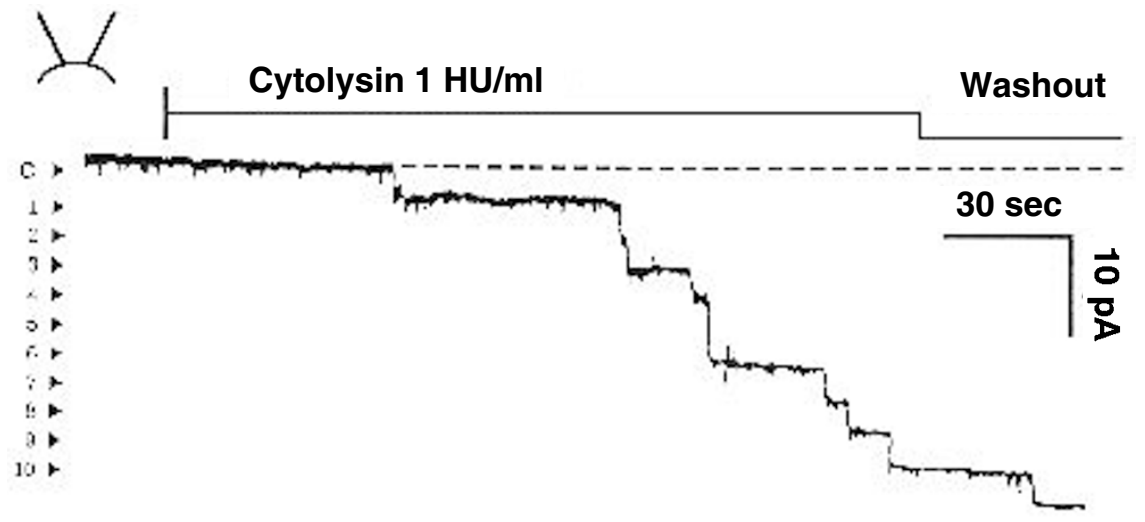

Figure 3. Effect of intracellularly applied $V$. vulnificus cytolysin on single channel currents in inside-out patches of CPAE cells. The bath and pipette solutions contained $140 \mathrm{mM} \mathrm{KCl}$ symmetrically, and the membrane potential was held at $-40 \mathrm{mV}$. Cytolysin was added to bath solution after excision of patches. The filter for the tracing reproduction was set at $300 \mathrm{~Hz}$. The number beside the current trace indicate the number to formed pores with $\mathrm{C}$ being the closed state.

of CPAE cell membrane. To investigate the relationship between pore formation of cytolysin and cytolysis, the releases of LDH from the cells were determined (Figure 4). Erythrocyte LDH was released by the cytolysin but its release was completely prevented by raffinose, an osmotic protectant. Whereas, LDH of CPAE cells was not released by the cytolysin treatment even at the absence of raffinose without affecting cellular LDH level (data not shown). The result indicates that CPAE cells are not ruptured by the cytolysin-induced pore formation, being resistant to osmotic lysis in contrast to erythrocytes.

Cellular ATP level was measured, because the depletion of cellular ATP level is known as a hallmark of the deterioration of cell metabolism. As shown in Figure 5, cellular ATP was continuously depleted as a function of the incubation time at $0.25 \mathrm{HU}$ of cytolysin, and approxi- mately $70 \%$ of total ATP was depleted within 60 min. When CPAE cells were also incubated with various concentrations of cytolysin, cellular ATP levels were decreased in a dose-dependent manner (Figure 6). Kim et al. (1993) demonst-rated that the pore formation on erythrocyte by $V$. vulnificus cytolysin is mediated by cholesterol on plasma membrane. Thus, to determine effect of cholesterol on ATP depletion of CPAE cells by cytolysin, cytolysin was incubated with cell suspensions containing cholesterol $(1 \mu \mathrm{g} / \mathrm{ml})$ (Figure 6). There was no leakage of ATP from CPAE cells into medium by the cytolysin (data not shown). The ATP depleting activity of the cytolysin on CPAE cells was completely inactivated by cholesterol. The redution of cellular ATP levels observed in this investigation was thought to be due to either the increase of ATP degradation or the decrease of ATP synthesis by mitochondrial 


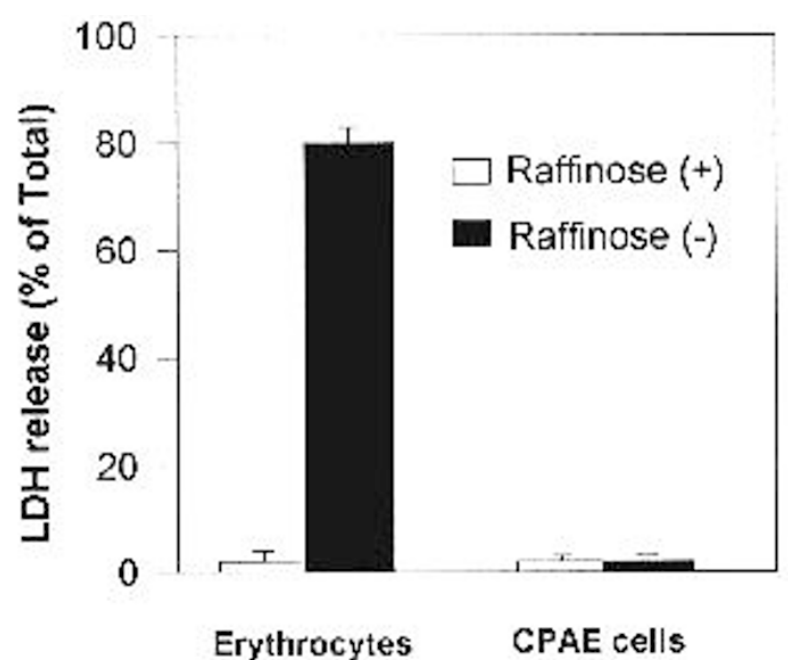

Figure 4. Effects of $V$. vulnificus cytolysin on $L D H$ releases from mouse erythrocytes and CPAE cells. Mouse erythrocytes $(0.35 \%)$ and CPAE cells $\left(1 \times 10^{6} \mathrm{cell} / \mathrm{sl}\right)$ were incubated with $1 \mathrm{HU}$ of cytolsin in a total volume of $1 \mathrm{ml}$ of PBS-BSA with or without 50 $\mathrm{mM}$ raffinose at $37^{\circ} \mathrm{C}$ for $30 \mathrm{~min}$. The released $\mathrm{LDH}$ was determined as described in "Materials and Methods". Each value denotes the mean \pm SD obtained from four separate experiments.

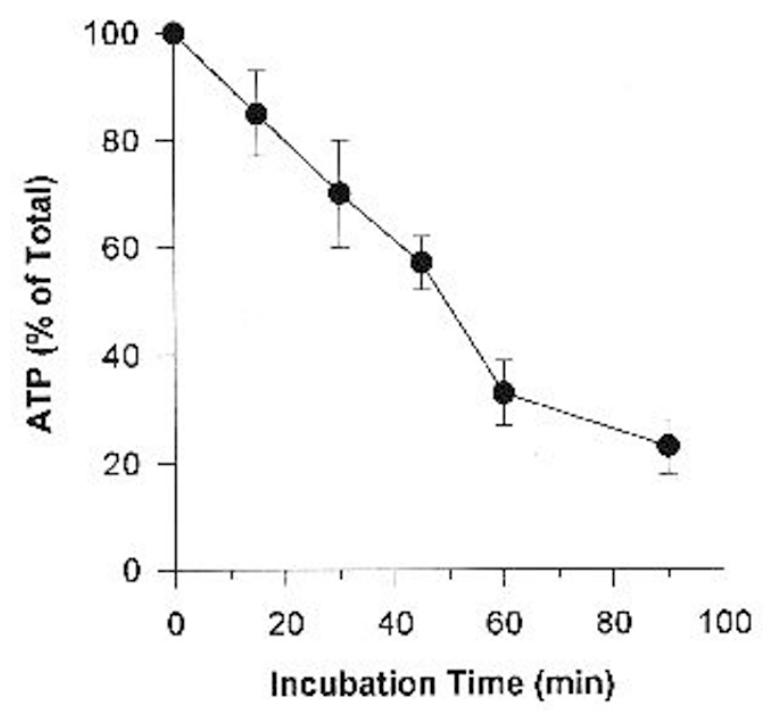

Figure 5. The time course of depletion of cellular ATP by V. vulnificus cytolysin. CPAE cells $\left(1 \times 10^{6} \mathrm{cells} / \mathrm{ml}\right)$ were incubated with $0.25 \mathrm{HU}$ of the cytolsin in a total volume of $1 \mathrm{ml}$ of PBS-BSA at $37^{\circ} \mathrm{C}$ The cellular ATP content at the given times was determined as described in "Materials and Methods". Each value denotes the mean \pm SD obtained from four separate experiments.

damage. Walev et al. (1993) demonstrated that the depletion of cellular ATP in keratinocytes by staphylococcal alpha-toxin was accompanied to the decrease of oxygen consumption, which was interpreted to reflect the breakdown of mitochondrial respiration. These results indicate that the toxic effect of $V$. vulnificus cytolysin on

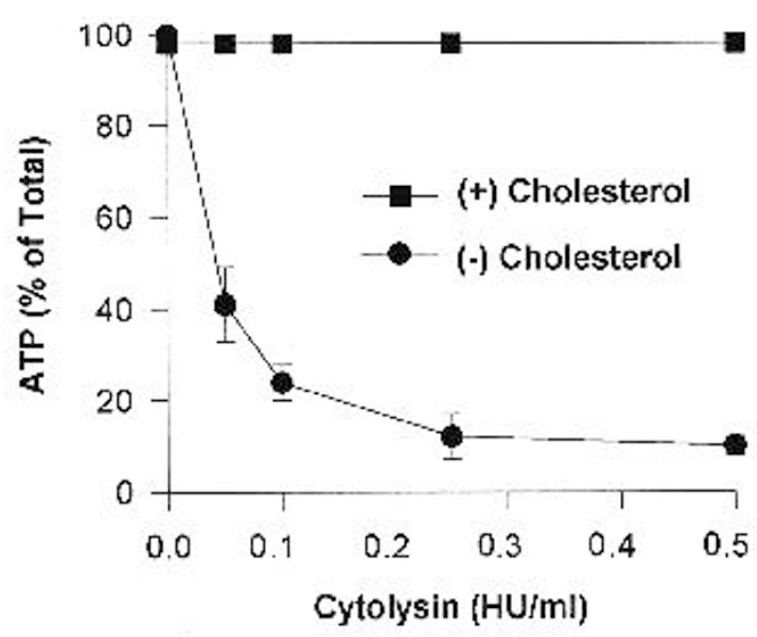

Figure 6. Effect of cholesterol on depletion of cellular ATP by V. vulnificus cytolysin. CPAE cells $\left(1 \times 10^{6} \mathrm{cell} / \mathrm{s} / \mathrm{ml}\right)$ were incubated with various concentrations of the cytolsin in a total volume of $1 \mathrm{ml}$ of PBS-BSA with or without cholesterol $(1 \mu \mathrm{g})$ at $37^{\circ} \mathrm{C}$ for 60 $\mathrm{min}$. The cellular ATP content was determined as described in "Materials and Methods". Each value denotes the mean $\pm \mathrm{SD}$ obtained from four separate experiments.

CPAE cells may be initiated by binding of the cytolysin to cholesterol on cell membrane, and that the death of the cell is due to the pore formation.

The results of this study suggest that the cell death of CPAE cell induced by $V$. vulnificus cytolysin is due to the depletion of cellular ATP by the formation of small transmembrane pores, which are permeable to monovalent ions, but not to LDH.

\section{Acknowledgement}

This work was supported in part by a fund from BioSafety Research Institute (Chonbuk National University, Korea).

\section{References}

Bernheimer, A. W. and Schwartz, L. L. (1963) Isolation and composition of staphylococcal alpha toxin. J. Gen. Microbiol. 30: 455-468

Bhakdi, S., Mackman, N., Nicaud, J.-M. and Holland, I. B. (1986) Escherchia coli hemolysin may damage target cell membranes by generating transmembrane pores. Infect. Immun. 52: 63-69

Blakes, P. A., Merson, H., Weave, R. E., Aollis, D. G. and Heublein, P. C. (1979) Disease caused by a marine Vibrio: Clinical characteristics and epidemiology. N. Eng. J. Med. 300: $1-5$

Brigham, K. L. and Meyrick, B. (1986) Endotoxin and lung injury. Am. Rev. Respir. Dis. 133: $913-927$

Chae, M. R.,Kim, H. N., Park, K. H., Rho, I. W., Kim, M. A., Kim, D. Y., Park, J. W. and Kim, H. R. (1996) Species-specific hemolysis by Vibrio vulnificus cytolysin. Exp. Mol. Med. 28: 95-99 
Gray, L. D. and Kreger A. S. (1985) Purification and characterization of an extracellular cytolysin produced by Vibrio vulnificus. Infect. Immun. 48: 62-72

Gray, L. D. and Kreger A. S. (1989) Mouse skin damage caused by cytolysin from Vibrio vulnificus and by Vibrio vulnificusinfection. J. Infect. Dis.155: 236-241

Hamill, O. P., Marty, A., Neher, E., Sakmann, B. and Sigworth, F. J. (1981) Improved patch clamp techniques for high-resolution current recording from cells and cell-free membrane patches. Pflügers Arch. 391: 85-101

Hollis, D. G., Weaver, R. E., Baker, C. N. and Thornberry, C. (1976) Halophilic Vibrio species isolated from blood cultures. J. Clin. Microbiol. 3: 425-431

Kim, H. R., Park, S. D., Park, J. W., Jeong, M. H, Kim, J. S. and Park, B. H. (1992) Purification and characterization of cytolysin produced by Vibrio vulnificus. Korean. $J$. Biochem. 24: 7-11

Kim, H. R., Rho, H. W., Jeong, M. H., Park, J. W., Kim, J. S., Park, B. H., Kim, U. H. and Park, S. D. (1993) Hemolytic mechanism of cytolysin produced from V. vulnificus. Life Sci. 53: $571-578$

Kook, H., Lee, S. E., Balk, Y. H., Chung, S. S. and Lee, J. H. (1996) V. vulnificus hemolysin dilates rat thoracic aorta by activating guanylate cyclase. Life Sci. 59: 41-47

Kreger A. S. and Lockwood, D. (1981) Detection of extracellular toxin(s) produced by Vibrio vulnificus. Infect. Immun. 33: 583-590

Kreger, A. S., Kothary, M. H. and Gray, L. D. (1988) Cytolytic toxins of Vibrio vulnificus and Vibrio damsela. Methods Enzymol. 165: 176-189

Krüll, M., Dold, C., Hippenstiel, S., Rosseau, S., Lohmeyer, J. and Suttorp, N. (1996) Escherichia coli hemolysin and Staphylococcus aureus $\alpha$-toxin potently induce neutrophil adhesion to cultured human endothelial cells. J. Immunol. 157: 4133-4140

Lundin, A. (1978) Determination of creatine kinase isoenzymes in human serum by an immunological method using purified firefly luciferase. Methods Enzymol. 57: 56-65

Park, J. W., Ma, S. N.,Song, E. S., Song, C. H., Chae. M. R., Park, B. H., Rho, H. W. Park, S. D. and Kim, H. R. (1996) Pulmonary damage by Vibrio vulnificus cytolysin. Infect. Immun. 64: 2873-2876
Park, J. W., Jang, T. A., Rho, H. W., Park, B. H., Kim, N. H. and Kim, H. R. (1994) Inhibitory mechanism of $\mathrm{Ca}^{2+}$ on the hemolysis caused by Vibrio vulnificus cytolysin. Biochim. Biophys. Acta 1194: 166-170

Park, S. D., Shon, H. S. and Joh, N. J. (1991) Vibrio vulnificus septicemia in Korea: Clinical and epidemiologic findings in seventy pationts. J. Am. Acad. Dermatol. 24: 397403

Rinaldo, J. E. and Rogers,R. M. (1986) Adult respiratory distress syndrome. N. Engl. J. Med. 315: 578-579

Rosengard, B. R. and Cochrane, D. E. (1983) Complement-mediated cytolysis: A quick, simple method for determining levels of immuno-globulin $E$ bound to mast cells. $J$. Histochem. Cytochem. 31: 441-444

Suttorp, N., Flöler, B., Schnittler, H., Seeger, W., and Bhakdi, S. (1990) Effects of Escherchia coli hemolysin endothelial cell funtion. Infect. Immun. 58: 3796-3801

Wahlefeld, A. W. (1983) UV-method with L-lactate and NAD. In Methods of Enzymatic Analysis (Bergmeyer, H.U. et al., eds), 3rd Edn., Vol. 3, pp. 126-133, Verlag Chemie, Weinheim

Walev, I., Martin, E., Janas, D., Mohamadadeh, M., Müller-Klieser, W., Kunz, L. and Bhakdi, S. (1993) Staphylococcal alpha-toxin kills human keratinocytes by permeabilizing the plasma membrane for monovalent ions. Infect. Immun. 61: 49724979

Yamanaka, H., Sugiyama, K., Furuta, H., Miyoshi, S. and Shinoda, S. (1990) Cytolytic action of Vibrio vulnificus haemolysin on mast cells from rat peritoneal cavity. J. Med. Microbiol. 32: 39-43 